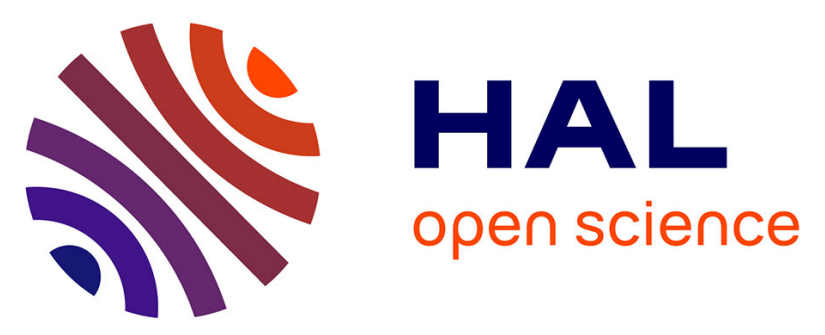

\title{
AN EXPERIMENTAL COMPARISON REGARDING BURR FORMATION ON MICROMILLING OF TITANIUM ALLOY TI-6AL-4V USING DIFFERENT EXPERIMENTAL SETUPS
}

Fabio Campos de Oliveira, Anna Carla Araujo

\section{To cite this version:}

Fabio Campos de Oliveira, Anna Carla Araujo. AN EXPERIMENTAL COMPARISON REGARDING BURR FORMATION ON MICROMILLING OF TITANIUM ALLOY TI-6AL-4V USING DIFFERENT EXPERIMENTAL SETUPS. 9º Congresso Brasileiro de Engenharia de Fabricação, 2017, Joinville, Brazil. hal-03226786

\section{HAL Id: hal-03226786 \\ https://hal.science/hal-03226786}

Submitted on 15 May 2021

HAL is a multi-disciplinary open access archive for the deposit and dissemination of scientific research documents, whether they are published or not. The documents may come from teaching and research institutions in France or abroad, or from public or private research centers.
L'archive ouverte pluridisciplinaire HAL, est destinée au dépôt et à la diffusion de documents scientifiques de niveau recherche, publiés ou non, émanant des établissements d'enseignement et de recherche français ou étrangers, des laboratoires publics ou privés. 


\section{AN EXPERIMENTAL COMPARISON REGARDING BURR FORMATION ON MICROMILLING OF TITANIUM ALLOY TI-6AL-4V USING DIFFERENT EXPERIMENTAL SETUPS}

COBEF2017-0286

Fábio de Oliveira Campos, fo.campos@mecanica.coppe.ufrj.br ${ }^{1}$

Anna Carla Monteiro Araujo, anna@ mecanica.ufrj.br ${ }^{2}$

${ }^{1}$ COPPE/Universidade Federal do Rio de Janeiro, Aven. Horácio Macêdo, 230, Centro de Tecnologia, fundos Bloco G, Ilha do Fundão, Cidade Universitária, CEP 21941914

${ }^{2}$ COPPE/Universidade Federal do Rio de Janeiro, Aven. Horácio Macêdo, 230, Centro de Tecnologia, Bloco G - Sala 204, CEP 21941914

Abstract. Titanium and its alloys, especially the Ti-6Al-4V alloy, are used on the manufacturing of dental implants and a deeper understanding of the micromachining of these materials is demanded. Burr formation is one of the parameters that can be used to study the machinability of a material and is a key factor on micromilling. Due to the small dimensions of the cutting geometry, deburring in micromachining is a difficult process. Hence minimizing burr formation is a major preoccupation in micromilling. Different authors found different scales when measuring burr formation. Therefore this work has the objective of presenting a comparison between two batches of experiments performed using different microtools and machine-tools and similar cutting parameters, and to find an optimal cutting speed regarding burr formation for one of the experimental setup. It was found that using a different experimental setup drastically changed burr formation results.

Keywords: micromachining, titanium, burr, cutting parameters, forces.

\section{INTRODUCTION}

Titanium and its alloys are used in the biomedical industry, especially for manufacturing implants, due to their excellent corrosion and wear resistance and biocompatibility. However, inherent properties as low thermal conductivity, low Young Modulus of $114 \mathrm{GPa}$ and the maintenance of high hardness and strength at elevated temperatures, make titanium and titanium alloys to be considered hard-to-machine materials (Kikuchi and Okuno, 2004, Veiga et al, 2013). Also, micromachining has gained a lot of attention in the last years on applications in biomedical, aerospace, electronics and others industries and micromilling is one of the most flexible micromachining process as it presents the possibility of machining complex geometries as curvatures and 3D cavities (Thepsonthi and Ozel, 2012).

Burr formation is one of the parameters that can be used to study the machinability of a material and is a key factor on micromilling. Due to the small dimensions of the cutting geometry, deburring in micromachining is a difficult process. Hence minimizing burr formation is a major preoccupation in micromilling. There are several studies performed on the machinability of different steels (Ding et al, 2010, Ucun et al, 2013, Zhu et al, 2013), but few on the machinability of titanium and titanium alloys considering micromilling. Even more scarce are the ones that take into consideration burr formation. Ozel et al (2011), for an example, compared results using carbide tools with and without cBN coating regarding surface finish, burr formation and tool wear during micromilling of Ti-6Al-4V. The results indicated good improvements when using a coated tool. Kim et al (2014) performed a machinability analysis regarding cutting forces, burr formation, chip morphology and tool wear during micromilling of Ti-6Al-4V varying cutting speed and feed per tooth. They concluded that feed per tooth was the main parameter that presented influence on cutting forces and burr formation. Bajpai et al (2013) analyzed burr formation and surface quality on micromilling of Ti-6Al$4 \mathrm{~V}$ varying depth of cut $(10-50 \mu \mathrm{m})$, feed $(1-5 \mu \mathrm{m})$ and cutting speed $(16-141 \mathrm{~m} / \mathrm{min})$. Results showed that increasing all parameters lead to a better surface finishing.

Despite the studies performed on analyzing burr formation during the micromilling of titanium, there is a variation on the scale of the values found by different authors. This work has the objective of presenting an attempt to reproduce a design of experiments in two different labs in micromilling of ASTM F136 Ti-6Al-4V, using different microtools and machine-tools and similar cutting parameters, and to find an optimal cutting speed regarding burr formation for one of the experimental setup. 


\section{MATERIALS AND METHODS}

The experiments were performed in two different labs using different tool supplies. The first batch was carried out in the Machine Tool Systems Research Lab at the University of Illinois at Urbana-Champaign (UIUC) on a Microlution Inc. Chicago® micromilling machine with three axis, maximum spindle speed of $50000 \mathrm{rpm}$ and axis resolution of 0.02 $\mu \mathrm{m}$ without cutting fluid. Performance Micro Tool ${ }^{\circledR}$ (PMT) tungsten carbide microtools of $0.508 \mu \mathrm{m}$ diameter without coating and with two flutes were used. Microtool cutting edge radius of 1-2 $\mu \mathrm{m}$ was measured using a Jeol® $6060 \mathrm{LV}$ scanning electron microscope (SEM). It was used a spindle speed of $14000 \mathrm{rpm}$, a feed per tooth range from 1 to 4 $\mu \mathrm{m} /$ tooth and axial depth of cut from 25 to $75 \mu \mathrm{m}$. To reference this batch of experiments, it will be used the tag batch $\# 1$.

A similar design of experiments was then reproduced in the Centro de Estudos de Fabricação e Comando Numérico at the Universidade Federal do Rio de Janeiro (UFRJ), using a CNC Mini Mill/GX micromilling machine-tool from Minitech Machinery Corporation ${ }^{\circledR}$ with three axis, maximum spindle speed of $60000 \mathrm{rpm}$ and axis resolution of $0.78125 \mu \mathrm{m}$ without cutting fluid. Mitsubishi Materials tungsten carbide microtools of $0.500 \mu \mathrm{m}$ diameter without coating and with two flutes were used. Microtool cutting edge radius of $2-3 \mu \mathrm{m}$ was measured using a .Jeol JSM6064LV SEM. It was used a spindle speed of $14000 \mathrm{rpm}$, a feed per tooth range from 1 to $4 \mu \mathrm{m} /$ tooth and axial depth of cut from 20 to $60 \mu \mathrm{m}$. To reference this batch of experiments, it will be used the tag batch \#2.

The experiments consisted of machining slots on pre-machined Ti-6Al-4V samples. The material used in all experiments is from the same batch of the same supplier, presenting the same microstructure and mechanical properties. The samples were pre-machined in order to guarantee a work surface orthogonal to the spindle axis and minimal depth of cut variation during the cutting process. The slots were machined on the same orientation regarding the material microstructure.

After analyzing and comparing the results from both batch of experiments, it was clear that the results were extremely different, especially regarding burr formation, an important parameter to characterize the quality of the machining process. Therefore, a third batch of experiments was carried out at UFRJ in order to find an optimal cutting speed regarding burr formation for the experimental setup of the lab. It was used constant feed per tooth and depth of cut of $2.5 \mu \mathrm{m} /$ tooth and $40 \mu \mathrm{m}$. A spindle speed range from 12000 to $28000 \mathrm{rpm}$ was defined with nine levels equally spaced. Burrs were measured in three different points of the slots. To reference this batch of experiments, it will be used the tag batch \#3.

Table 1 shows the different equipment used to analyzed the microtool and the burr formation in both machining labs.

Table 1 - Equipment specifications.

\begin{tabular}{|c|c|c|}
\hline$L a b$ & UFRJ & UIUC \\
\hline Machine Tool & CNC Mini Mill/GX & Microlution Inc. Chicago® \\
\hline Microtool & Performance Micro Tool® & Mitsubishi Materials® \\
\hline Microtool analysis & Jeol® JSM-6064LV & Jeol® 6060 LV \\
\hline Groove/Burr Analysis & $\begin{array}{l}\text { Handheld Digital Microscope/ } \\
\text { Jeol® } 6060 \text { LV }\end{array}$ & $\begin{array}{l}9100 \text { Series Video Inspection } \\
\text { from S-T Industries }{ }^{\circledR}\end{array}$ \\
\hline Burr measurement & $\begin{array}{l}\text { Form Talysurf Intra } \\
\text { profilometer }\end{array}$ & Dektak® 3030 profilometer \\
\hline
\end{tabular}

For the batch \#3, the cutting forces were measured for a deeper understanding of the process. The acquisition of the cutting force signal was performed using also a Kistler® 5070A10100 charge amplifier, a National Instruments ${ }^{\circledR}$ acquisition board NI USB-6551 and the software LabView Signal Express. The acquisition frequency of the force signal was $40000 \mathrm{~Hz}$.

\section{RESULTS AND DISCUSSION}

In this section, the results and comparison regarding the experiments performed in both labs are presented as well as the analysis of the experiments to find the optimal cutting speed regarding burr formation for the experimental setup specified.

\subsection{Microtool}

Figure 1 shows the scanning electron microscope images of the tools. Although the diameter of both tools is the same, the geometry of the cutting edge is different. However, the dimension of the cutting edge radius are not very 
different. The cutting edge dimension of the PMT tool is 1-2 $\mu \mathrm{m}$, while the cutting edge of the Mitsubishi tool is $2-3$ $\mu \mathrm{m}$. Nevertheless, even a small difference on the cutting edge radius can imply a big difference on the cutting process as the minimum chip thickness can be different.

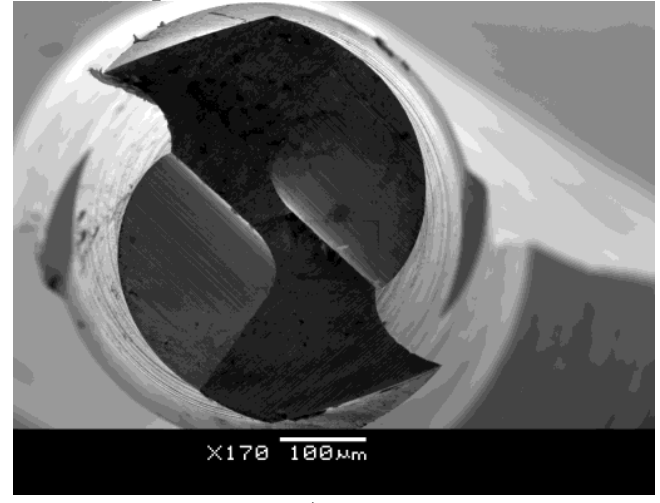

a)

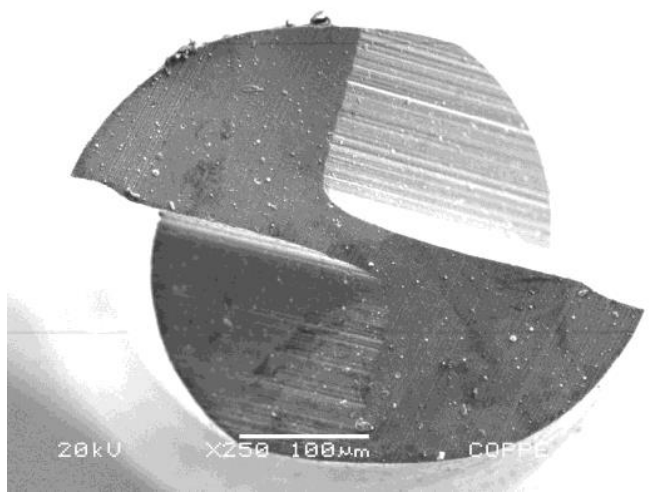

b)

Figure 1 - SEM images of the microtools. a) Performance Micro Tool; b) Mitsubishi Materials.

\subsection{Burr formation comparison}

As stated before, the first and second batch of experiments were performed with similar cutting parameters. The only difference was a small change of the axial depth of cut. Despite this difference, the results of both batch were compared. It was preferred to present the results only of the standard points $(0,0)$ of the design of experiments as the objective of the present work is not to analyze the influence of the factors on some measurement.

Figure 2 shows the images of the slots machined with cutting parameters of: feed of $2.5 \mu \mathrm{m} /$ tooth and depth of cut of $50 \mu \mathrm{m}$ for the batch \#1 in Fig. 2a; and feed of $2.5 \mu \mathrm{m} /$ tooth and depth of cut of $40 \mu \mathrm{m}$ for the batch \#2 in Fig. $2 \mathrm{~b}$.

It can be seen from the images that there was a big discrepancy between the experiments regarding the burr formation. Although a smaller depth of cut favors the occurrence of burr, the difference on the depth of cut of both batches of experiments is not sufficient to explain the high burr occurrence on the experiments of batch \#2.

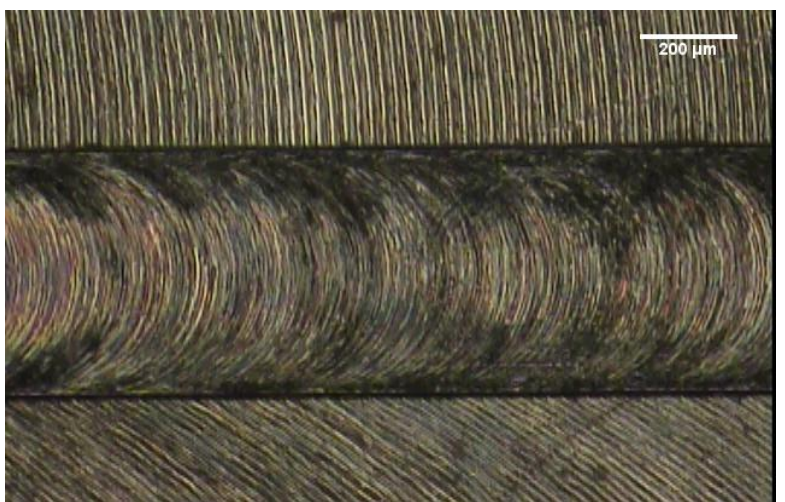

a)

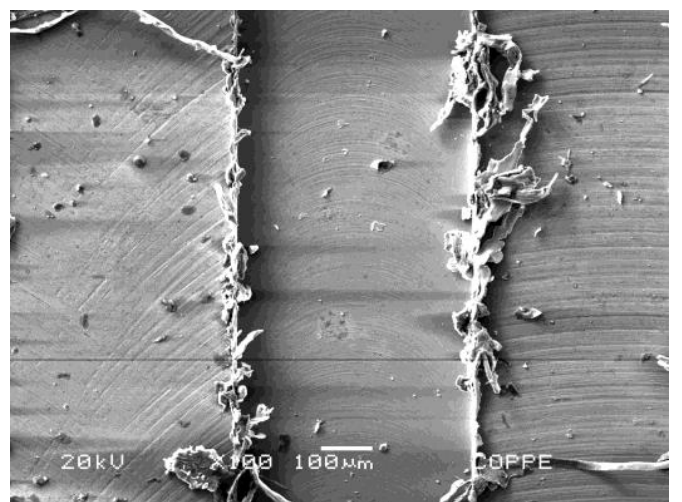

b)

Figure 2 - Scanning electron microscope images of the grooves: a) Batch \#1, feed of $2.5 \mu \mathrm{m} / \mathrm{tooth}$ and depth of cut of $50 \mu \mathrm{m}$; b) Batch \#2, feed of $2.5 \mu \mathrm{m} /$ tooth and depth of cut of $40 \mu \mathrm{m}$.

Even though a visual analysis of the images is sufficient to stablish that there was a great difference on burr formation for similar cutting parameters, top burrs height from both batch of experiments was measured and analyzed. Figure 3 a shows how the burr height was measured for each experiment.

Figure $3 b$ shows the comparison between top burr heights for the experiments of both batches for up and downmilling. The measurements, as expected, confirm the visual analysis done before. Also, for both batch of experiments, burr formation was slightly higher during up-milling than down-milling. Considering that the feed per tooth and the cutting speed used in both batch of experiments are the same and that the depths of cut are similar, we can suppose that this great difference in burr formation can be a result from the different tool and/or the different machine-tool. Another hypothesis is that because of the higher cutting edge radius, the minimum chip thickness for the second experimental setup is higher and with the specified feed per tooth, the ploughing phenomenon is occurring during the process. Also, the cutting speed used $(22 \mathrm{~m} / \mathrm{min})$ can be considered a low speed even for the titanium alloy, which is a hard to machine material. 

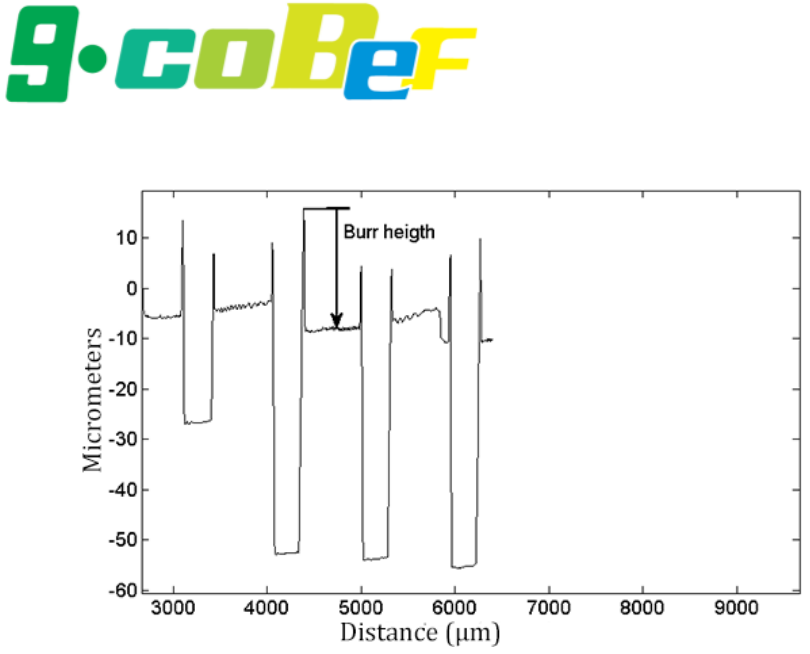

a)

Figure 3 - Analysis of burr formation: a) Measurement of top burr height; b) Comparison between burr height for batch \#1 (feed of $2.5 \mu \mathrm{m} /$ tooth and depth of cut of $50 \mu \mathrm{m}$ ) and batch \#2 (feed of $2.5 \mu \mathrm{m} /$ tooth and depth of cut of $40 \mu \mathrm{m})$.

Because of the results of the previous analysis, a third batch of experiments was carried in order to find an optimal cutting speed regarding burr formation. Therefore, nine equally spaced spindle speeds were selected between 12000 and $28000 \mathrm{rpm}$ for the third batch of experiments. Feed per tooth and depth of cut were kept constant and it was used the standard points of the previous design of experiments, as showed by Tab. 2.

Table 2 - Cutting speed used in batch \#3.

\begin{tabular}{c|cc}
\hline \multicolumn{3}{c}{ Feed per tooth $=\mathbf{2 . 5} \boldsymbol{\mu m} /$ tooth; Depth of cut $=\mathbf{4 0} \boldsymbol{\mu m}$} \\
\hline $\begin{array}{c}\text { Slot } \\
\text { Number }\end{array}$ & $\begin{array}{c}\text { Spindle Speed } \\
(\boldsymbol{r p m})\end{array}$ & Cutting Speed $(\mathbf{m} / \mathbf{m i n})$. \\
\hline 1 & 12000 & 18.8 \\
2 & 14000 & 22.0 \\
3 & 16000 & 25.1 \\
4 & 18000 & 28.3 \\
5 & 20000 & 31.4 \\
6 & 22000 & 34.5 \\
7 & 24000 & 37.7 \\
8 & 26000 & 40.8 \\
9 & 28000 & 44.0 \\
\hline
\end{tabular}

Figure 4 shows images taken with a Handheld Digital Microscope of the nine slots machined with different cutting speeds. From the image, on a visual analysis, it can be seen that a couple of the slots showed better results regarding burr formation. Figure 5 presents a closer image of the slots ' 3 ', ' 4 ' and ' 5 '. Analyzing the Figure 5, one can conclude that the slot number 4 , machined with spindle speed of $18000 \mathrm{rpm}\left(\mathrm{V}_{\mathrm{c}}=28.3 \mathrm{~m} / \mathrm{min}\right.$.), presented a smaller burr formation during the cutting process. Nevertheless, top burr height was measured for all slots for purposes of better comparison.

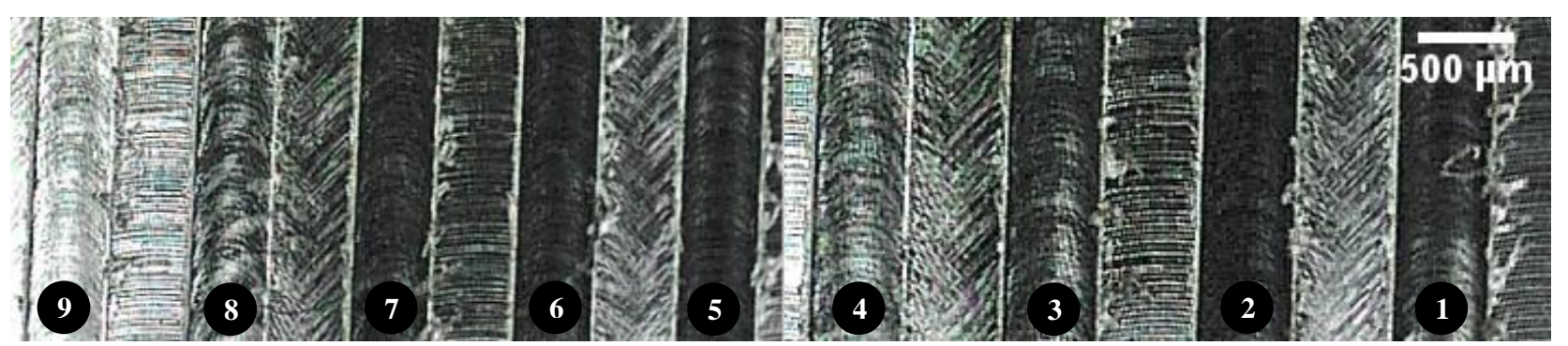

Figure 4 - Machined slots image taken with a Handheld Digital Microscope (slots width: $500 \mu \mathrm{m})$. 


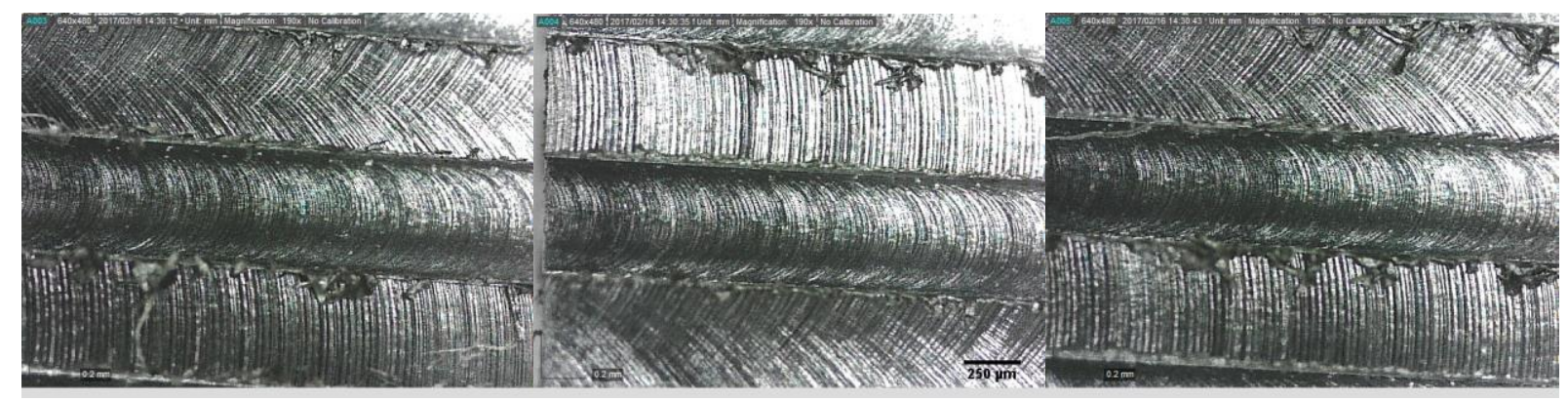

Figure 5 - Slots machined with 25.1, 28.3 and $31.4 \mathrm{~m} / \mathrm{min}$. (slots width: $500 \mu \mathrm{m}$ ).

Figure 6 shows the measurements of burr heights for all slots. It can be seen that slot 4 , machined with spindle speed of $18000 \mathrm{rpm}$, presented less burr formation than the others, despite the high variation of the measurements, a typical characteristic of burr formation monitoring. It can be seen that for almost all slots there was more burr formation during the up-milling part of the cutting process. Although visually the results for the slot 4 seamed a lot better than the ones of the batch \#2 and of the others slots, the burr height values show a minor difference between the slot 4 and the result showed for batch \#2. However, burr measurement using a profilometer is not $100 \%$ precise and is used as an estimation of the burr formation as burrs can be positioned in different ways, being short or long.

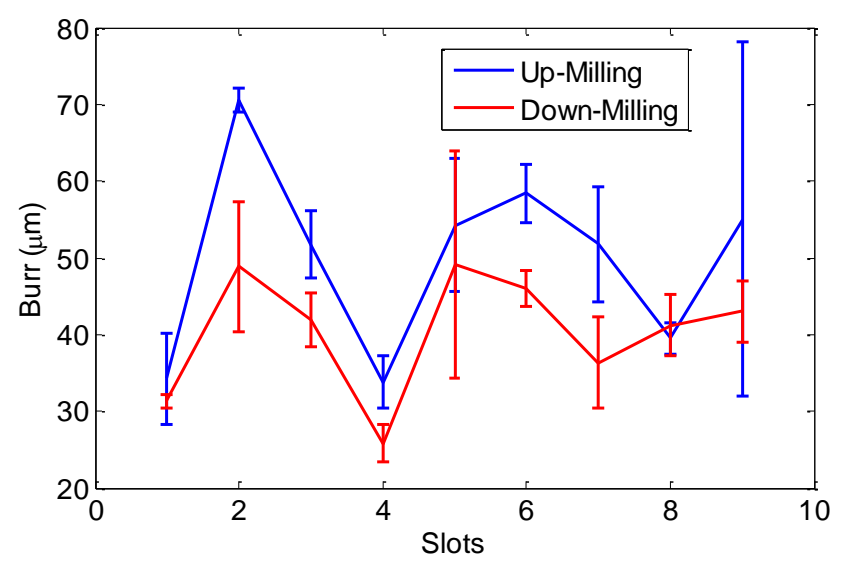

a)

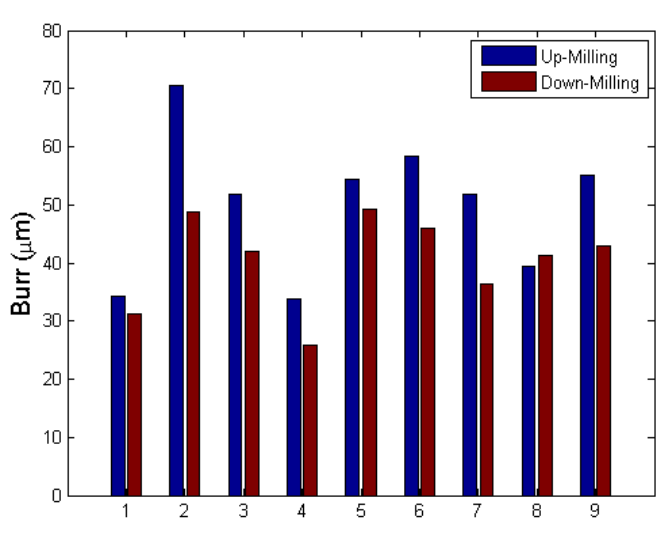

b)

Figure 6 - Top burr height measurements for slots 1-9: a) Graph with error bar representation using the standard deviation; b) Bar graph for a better visualization of the results.

\subsection{Cutting force measurements}

In order to further understand the process, cutting forces were measured during the performing of batch experiments \#3. The force signal was filtered using a low-pass filter with cut off frequency of $3000 \mathrm{~Hz}$. Cutting forces were analyzed considering the average of maximum resultant force per tool revolution for 40 revolutions. As an example, Fig. 7a shows the cutting force of slot \#1 on $\mathrm{X}$ (feed direction) and $\mathrm{Y}$ directions for three tool revolutions and Fig. 7b shows the resultant cutting force, also for three revolutions.

It can be seen from Fig. 7a that the force signal does not present two force peaks per revolution as it was expected. One hypothesis is that only one tooth is performing almost all the cutting during the machining process. This can happen due to an error on the tool fixing and the tool is inclined or due to an early breakage of one of the teeth. 


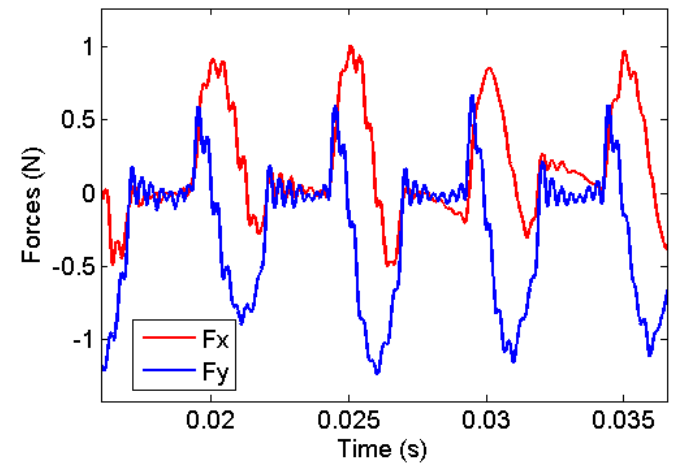

a)

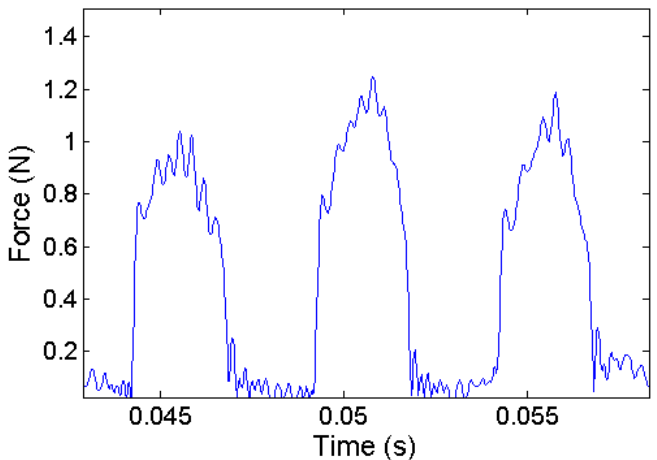

b)

Figure 7 - Cutting force measurement for slot \#1: a) Cutting force on direction X and Y; b) Resultant cutting force.

Figure 8 shows the evolution of the maximum resultant cutting force when increasing the cutting speed with a margin of error inside a confidence level of $95 \%$. For the first three cutting speeds, there was an increase on the cutting force with the increase of the cutting speed. For $18000 \mathrm{rpm}$ and higher spindle speeds, cutting force can be considered to be constant due to the error bars. A possible reason for the initial increase on the cutting force is an increase on machine vibrations, which would also explain the increase on the error bar with the increase of the cutting speed.

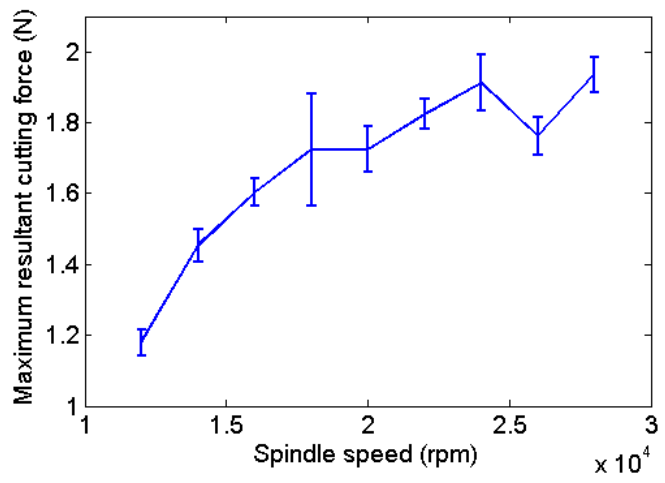

Figure 8 - Cutting force evolution when increasing cutting speed.

\section{CONCLUSIONS}

In this work, two batch of micromilling experiments were performed on Ti-6Al-4V samples using similar cutting parameters, but different tools and machine-tools. Burr formation on both batch of experiments were analyzed and a third batch of experiments was performed to find the optimal cutting speed regarding burr formation using the equipment of the second batch. The main conclusions of this work are:

- Considering the comparison between the burr formation analysis of the batches of experiments \#1 and \#2, it can be concluded that the micromilling process is very difficult to reproduce as a change in variables like the microtool manufacturer and the machine-tool that was used can drastically change the results;

- An attempt to reproduce batch of experiments \#1 (with a small difference on the depth of cut) using a microtool from another manufacturer and a different machine-tool lead to a completely different result regarding burr formation. Top burr heights were measured and the dimensions were considerably higher in the batch \#2;

- This result could be explained by the different tool and machine-tool used; by the higher cutting edge of the microtool, meaning that the feed specified is still below the minimum chip thickness; or even by the low cutting speed used, as small cutting speeds lead to higher burr formation;

- For the third batch of experiments, varying the cutting speed, a spindle speed of $18000 \mathrm{rpm}$ showed the best result regarding burr formation; 
- Analyzing the cutting forces, it could be seen that one tooth was performing almost the entire cutting as the force profile was different than the one expected. Also, it was found a tendency of the cutting force to increase when increasing the cutting speed.

For future analysis, the authors expect to be able to analyze the burr formation behavior using the optimal cutting speed and varying the feed per tooth. Also, the microtool can be analyzed after the experiments in order to better characterize the process.

\section{ACKNOWLEDGEMENTS}

The authors thank financial support from CNPq, Universal Project Number 481406/2013-1, and Capes for the Sandwich Scholarship. The Brazilian researchers would thank the University of Illinois at Urbana Champaign and Prof. Shiv Kapoor for the technical support and friendship during the research.

\section{REFERENCES}

Bajpai, V., Kushwaha, A. and Singh, R., 2013, Burr formation and surface quality in high speed micromilling of titanium alloy (Ti6Al4V), Vol. 2.

Ding, H., Ibrahim, R., Cheng, K. and Chen, S., 2010, Experimental study on machinability improvement of hardened tool steel using two dimensional vibration-assisted micro-end-milling, International Journal of Machine Tools \& Manufacture, 50 1115-1118.

Kikuchi, M. and Okuno, O., 2004, Machinability evaluation of titanium alloys, Dental Materials Journal, 23 (1) pp. $37-$ 45.

Kim, D.H., Lee, P.H. and Lee, S.W., 2014, Experimental study on machinability of Ti6Al4V in micro end-milling, Proceedings of the World Congress on Engineering.

Ozel, T., Thepsonthi, T., Ulutan, D. and Kaftanolu, B., 2011, Experiments and finite element simulations on micromilling of Ti6Al4V alloy with uncoated and cbn coated micro-tools, CIRP Annals - Manufacturing Technology, 60 (1) $85-88$.

Thepsonthi, T. and Ozel, T.,2012, Multi-objective process optimization for micro-end milling of Ti6A14V titanium alloy, The International Journal of Advanced Manufacturing Technology, 63 (9) pp. 903-914.

Ucun, I., Aslantas, K. and Bedir, F., 2013, An experimental investigation of the effect of coating material on tool wear in micro milling of Inconel 718 super alloy, Wear, 300 8-19.

Veiga, C., Davim, J. and Loureiro, A., 2013, Review on machinability of titanium alloys: The process perspective, Reviews on Advanced Materials Science, 34 (2) pp. 148-164.

Zhu, J., Kim, H.J. and Kapoor, S.g., 2013, Microscale Drilling of Bulk Metallic Glass, Journal of Micro- and NanoManufacturing, 1(4), 041004.

\section{RESPONSIBILITY NOTICE}

The authors are the only responsible for the printed material included in this paper. 